\title{
O ensino da Língua Inglesa em tela: a mise-en-scène ${ }^{1}$
}

\author{
Mateus da Rosa Pereira ${ }^{2}$ \\ Danielle dos Santos Espíndula ${ }^{3}$ \\ Clarice Maria de Sousa Portela Germann Teixeira ${ }^{4}$
}

\section{Resumo}

Embora o cinema seja um dos recursos mais apreciados pelos professores e alunos de língua estrangeira, observamos, de um lado, a carência de variedade nas atividades com filmes em sala de aula e, de outro, a falta de embasamento teórico e uma relação frágil entre as atividades com filmes e os planos de ensino propostos. Portanto, os professores que desejam desenvolver atividades mais efetivas para ensinar inglês com o uso de filmes poderiam se beneficiar com um conjunto de ferramentas elementares provenientes de uma interface dos estudos do cinema, da linguística aplicada e da semiótica. Assim, este trabalho tem como objetivo explorar as relações entre a linguagem fílmica e o ensino de inglês, de forma que resulte em propostas pedagógicas práticas e claramente embasadas nas teorias do cinema, da semiótica e da linguística aplicada, com ênfase nos elementos da mise-en-scène. Adotando um referencial teórico básico e uma proposta metodológica de uso do cinema em aulas de Língua Inglesa, o artigo apresenta exemplos de aplicação que levam em consideração o contexto educacional de um curso de informática integrado ao ensino médio do Instituto Federal de Educação, Ciência e Tecnologia do Rio Grande do Sul (IFRS). Embora os resultados deste trabalho ainda sejam incipientes, tendo em vista o caráter inacabado da pesquisa de que faz parte, podemos afirmar que a aproximação entre a linguagem cinematográfica e o ensino da Língua Inglesa representa uma via fértil para o enriquecimento do processo de ensino-aprendizagem dessa língua estrangeira.

Palavras-chave: Ensino de Língua Inglesa. Cinema em Sala de Aula. Filmes.

\begin{abstract}
Although films are among the favorite teaching resources for teachers and students of foreign languages, we have often witnessed, on the one hand, a lack of variety of task formats using films and, on the other, fragile theoretical foundations and a weak link between activities and students' needs as detailed in course syllabuses and lesson plans. Therefore, teachers who want to design more effective activities to teach English using films could greatly benefit from a set of elementary theoretical tools from the domains of film studies, applied linguistics and semiotics. This paper aims to explore the relationship between film language and applied linguistics, so as to generate pedagogical solutions that are practical and clearly based on key definitions from film studies, semiotics and applied linguistics, especially focused on the elements of mise-en-scène. Using a basic theoretical framework and a practical methodological proposal to use films in ELT, this paper presents examples of classroom applications which take into account the Brazilian public educational context of a computer science program integrated into the high school of a Federal Institute in the State of Rio Grande do
\end{abstract}

\footnotetext{
${ }^{1}$ Este artigo é o resultado do trabalho desenvolvido ao longo de 2017, no âmbito do projeto de pesquisa "O uso do cinema no ensino da língua inglesa: a mise-en-scène", com discentes do curso de licenciatura em Letras do campus Osório do IFRS. Neste ano, o projeto concentra-se no desenvolvimento de atividades pedagógicas para o contexto de um curso técnico em informática integrado ao ensino médio do IFRS.

2Professor de Ensino Básico, Técnico e Tecnológico, na área de Letras (Português e Inglês), no Campus Osório do Instituto Federal de Educação, Ciência e Tecnologia do Rio Grande do Sul (IFRS). Possui Licenciatura em Letras Língua Portuguesa, Língua Inglesa e Literaturas Correspondentes pela Universidade Federal do Rio Grande (FURG), mestrado em Letras Inglês e Literatura Correspondente pela Universidade Federal de Santa Catarina (UFSC) e doutorado em Letras (Literatura Comparada) pela Universidade Federal do Rio Grande do Sul (UFRGS).E-mail: mateusdarosapereira@yahoo.com.br

${ }^{3}$ Graduanda do curso de Licenciatura em Letras - Português/ Inglês pelo Campus Osório do IFRS. E-mail: danielle.espindula@hotmail.com

${ }^{4}$ Graduanda do curso de Licenciatura em Letras - Português/ Inglês pelo Campus Osório do IFRS. E-mail: claricemsportela@hotmail.com
} 
Sul (IFRS). Even though the outcomes presented herein are not yet mature, as the research to which they belong is still in progress, we are convinced that establishing connections between film language and English language teaching is a powerful path towards enhancing the quality of English language teaching and learning.

Keywords: English Language Teaching. Films in the Classroom. Cinema.

\section{Introdução}

O cinema é um dos recursos mais utilizados por professores de Língua Inglesa (LI), por ser muito apreciado pelos alunos e por possibilitar que os discentes tenham contato com linguagem autêntica e reproduzível, entre outros motivos. Entretanto, observa-se a carência de variedade nas atividades com filmes em sala de aula, sendo que a maior parte dos professores insiste somente em atividades de preenchimento de lacunas ou em perguntas de compreensão, trabalhando apenas os aspectos narrativos dos filmes e desprezando uma série de outros elementos, como a edição, o som e a mise-en-scène. Ainda mais alarmante é a falta de objetivos claros e de uma consciência a respeito dos pressupostos teóricos das propostas de trabalho com o cinema em aulas de LI a partir das relações entre a linguística aplicada e a teoria fílmica. Considerando essas carências, o presente artigo se coloca como uma reflexão sobre tais entrecruzamentos e sobreposições entre a teoria e a prática docente com o intuito de enriquecer a formação continuada de professores de LI.

Se, por um lado, a maioria de nós concordaria que existem, virtualmente, infinitas possibilidades de se trabalhar com filmes na sala de aula de língua estrangeira, por outro, percebe-se a repetição de apenas alguns tipos de atividades. Em um extremo, podemos perceber o que Arizio Sweeting (2010) chama de "síndrome" de preenchimento de lacunas:

Para muitos professores de Língua Inglesa no mundo todo, o uso abusivo de exercícios de preenchimento de lacunas ao utilizar filmes em sala de aula é a norma, o que gera o que eu chamo de "Síndrome do Preenchimento de Lacunas", isto é, uma abordagem um tanto mecânica que condiciona a experiência do aluno com o filme ao seu texto, para que preencha frases repletas de lacunas. (SWEETING, 2010, online, tradução nossa ${ }^{5}$ ).

\footnotetext{
${ }^{5}$ It is the norm for many English language practitioners around the world to overuse gap-fill exercises when using films in the classroom, generating what I call the "Gap-fill Syndrome", i.e. a rather mechanical approach which conditions learners' viewing to the film text in order to fill out gap-filled sentences.
} 
Dentre tantas possibilidades, percebemos que, com frequência, os professores utilizam o cinema para introduzir um tema que será o fio condutor de algumas aulas, ou para contextualizar uma época de maneira a fornecer aos alunos uma ideia de como era o mundo em tal lugar em tal época; ou, ainda, os professores utilizam muito os filmes para discutir elementos narrativos, tais como a motivação de um protagonista ou um final alternativo. Note que algumas dessas ideias são comuns e muito interessantes. Entretanto, algumas das atividades que funcionam muito bem no ensino de L1 podem não ser efetivas no ensino de $L 2$ - especialmente nos níveis iniciais de proficiência, que constituem a grande parte do nosso ensino básico no Brasil - , pelo simples fato de que os alunos ainda não conseguem sustentar um debate na língua estrangeira ou apresentam grandes dificuldades para compreender filmes exibidos com áudio original a ponto de analisar seus elementos narrativos.

Apesar disso, os alunos geralmente gostam muito de praticamente qualquer atividade com o uso de filmes e, por isso mesmo, os filmes são tratados como uma recompensa na sala de aula, o que tem muitas implicações. Em primeiro lugar, nessas situações os alunos só poderão ter uma atividade com cinema se se comportarem bem, ou seja, a atividade com o material audiovisual é inconscientemente considerada dispensável. Se os alunos não se comportarem bem, não a farão; apenas perderão a parte divertida da aula. Assim, uma das questões que nos confronta e que tentamos explorar neste trabalho, enquanto professores de língua estrangeira, é: existem alguns tópicos no ensino de LI que podem ser aprendidos com mais eficiência e eficácia com filmes, de forma que torne o seu uso essencial ou fortemente recomendável?

A outra implicação que surge do fato de os filmes serem tratados como uma recompensa ao bom comportamento da turma de língua estrangeira - e aqui, ao menos com base em nossa experiência de docência, isso se aplica tanto aos cursos livres como ao ensino médio e até mesmo ao ensino de LI em licenciaturas - é que o próprio nível de satisfação dos alunos funciona como uma armadilha. Em outras palavras, os alunos gostam tanto das atividades com filmes que, mesmo que o professor não tenha estabelecido objetivos didáticos claros ou não tenha definido uma relação tão estreita com o plano de ensino mais amplo do qual a aula faz parte, aquele dia da atividade com cinema será 
considerado um sucesso na perspectiva dos alunos e, consequentemente, na do professor. É assim que podemos explicar por que tantos ótimos professores decidem, quando o plano de ensino permite (ou seja, quando não estão atrasados no cronograma), passar um filme, às vezes ocupando dois ou até quatro períodos, posteriormente aplicando algumas questões de compreensão. No entanto, como bem lembra Khan (2015, p. 50, tradução nossa ${ }^{6}$ ) ao professor que deseja trabalhar com filmes no ensino da LI, "tenha um objetivo relativamente claro que justifique o uso do filme, caso contrário a aula se degenera e o professor passa a desempenhar a função de uma babá". Dependendo do professor, os componentes linguísticos podem ser tratados de forma mais ou menos aprofundada ou superficial, e, nos piores casos, as atividades pedagógicas funcionam apenas como algo que justifique (para os pais ou para a coordenação) uma atividade tão divertida e bem-sucedida.

Fica claro, colocando nesses termos, que atividades assim propostas têm fragilidades do ponto de vista do processo de ensino-aprendizagem de línguas estrangeiras. Em primeiro lugar, apesar de a motivação ser uma grande aliada na aprendizagem de uma L2, essas atividades devem justificar-se primordialmente por atender aos objetivos do plano de ensino, de maneira concretamente relacionada às habilidades e aos conteúdos desenvolvidos ao longo da unidade ou da sequência didática mais ampla. Em total acordo com Khan (2015, p. 50, tradução nossa ${ }^{7}$ ), "a solução para o ensino de LI não está nos filmes; ela está no que os professores de inglês fazem com os filmes na aula de língua estrangeira". Com isso em mente, percebemos que em poucos casos exibiríamos um filme todo em sala de aula ${ }^{8}$. Quando consideramos com clareza os objetivos que pretendemos alcançar com o uso de um material audiovisual, também se torna claro o tanto do filme que é necessário mostrar para desenvolver a atividade pedagógica. Isto é, o foco deve estar na atividade, não no filme.

Entretanto, não nos basta ter consciência dessa necessidade pedagógica para que, enquanto professores de língua estrangeira, possamos articular as atividades de

\footnotetext{
${ }^{6}$ have a relatively lucid objective behind utilising the film, otherwise the lesson degenerates into a baby-sitting situation.

${ }^{7}$ English teaching solutions don't lie in films; they lie in what English teachers do with films in the ESL classroom. ${ }^{8}$ Uma exceção a esse princípio no uso de filmes em aulas de língua estrangeira é a sequência de atividades desenvolvidas e relatadas por Alice Canal (2017), em que a professora dedica algumas semanas ao trabalho com o filme Um conto chinês, de forma muito relevante e interessante, a partir das necessidades do seu plano de ensino na disciplina de Língua Espanhola.
} 


\section{LínguaTec}

desenvolvimento linguístico com o cinema. Precisamos, além disso, desenvolver capacidades técnicas mínimas para perceber como, em nossas aulas específicas, podemos tirar o melhor proveito dos filmes para atender a objetivos específicos no ensino da língua estrangeira. É nesse sentido que este trabalho visa explorar os elementos que constituem a mise-en-scène -cenário, figurino, maquiagem, iluminação e atuação - , para que posteriormente sejam estabelecidas conexões entre esses aspectos e as possibilidades de atividades pedagógicas, especialmente no ensino de LI no ensino médio técnico. O principal objetivo deste trabalho não é, todavia, fazer uma descrição semiótica do cinema a partir da linguística, mas, antes, iniciar a construção de uma proposta metodológica que aproxime componentes específicos da linguagem cinematográfica com conteúdos que constituem os planos de ensino básico da LI.

Na primeira parte do artigo, serão revisados alguns estudos cujo tema central é o ensino da LI com o uso de filmes, no intuito de mapear práticas e pressupostos pedagógicos. Na segunda parte, será explicitada a visão de como pode ser estabelecida a aproximação entre a linguagem cinematográfica e alguns elementos linguísticos. Em seguida, será apresentada uma caracterização de uma das técnicas cinematográficas mais marcantes e facilmente perceptíveis, a mise-en-scène. Posteriormente, serão desenvolvidas duas atividades didáticas que exemplificam a proposta metodológica em questão, criadas para o contexto do ensino técnico integrado ao ensino médio do IFRS. Ao final, são tecidas algumas considerações finais, que trazem algumas respostas e suscitam outros problemas a serem explorados nesse contexto.

\section{Do ensino da LI à linguagem cinematográfica (e vice-versa)}

Que o cinema pode ser um grande aliado no ensino da LI é uma afirmação da qual poucos professores discordariam, ainda mais com a crescente facilidade e a redução gradativa dos custos associados ao acesso e à reprodução de filmes em sala de aula, em grande parte ligadas ao desenvolvimento de Tecnologias da Informação e Comunicação e da Internet. Todavia, pressupondo que precisássemos defender a utilidade desse recurso 


\section{LínguaTec}

audiovisual para o ensino de LI, poderíamos lançar mão de um apanhado muito relevante da investigação de Atiya Khan (2015), que analisa os principais benefícios dessa combinação:

- Aprender com filmes é estimulante e divertido. Considerando que a motivação é um dos fatores cruciais para o aprendizado efetivo de uma língua estrangeira, mediante a orientação cuidadosa do professor os alunos têm a oportunidade de trabalhar uma série variada de aspectos linguísticos, aliando diversão e aprendizado.

- Os filmes fornecem cenários linguísticos autênticos e diversos. Com filmes, os alunos são confrontados com instâncias linguísticas do inglês tal como é usado em situações reais (ou representadas como tal) fora da sala de aula, de maneira interativa, expondo os alunos a expressões e fluxo de fala mais naturais do que em grande parte dos materiais didáticos disponíveis.

- Os filmes dispõem de um contexto visual. O cinema auxilia a construção da compreensão dos alunos possibilitando que eles ouçam os diálogos e também acompanhem o suporte visual de expressões faciais e gestual ao mesmo tempo, o que gera um incremento no seu foco de atenção.

- Filmes permitem ao professor e à turma variedade e flexibilidade. As quatro habilidades (fala, audição, leitura e escrita) podem ser trabalhadas, de forma isolada ou articulada, com bastante facilidade em atividades com o cinema.

Portanto, a questão não é se os professores podem usar filmes no ensino de LI, mas como utilizá-los. Ao trazerem filmes para a sala de aula de inglês, as práticas de professores de língua estrangeira aproximam a língua a ser ensinada e a linguagem cinematográfica, independentemente de qualquer teoria subjacente - sem aqui pressupor um julgamento de valor. No entanto, parece não haver quase nenhuma orientação metodológica sobre como lidar com os filmes de maneira efetiva e específica, principalmente considerando dois desafios que gostaríamos de retomar de forma explícita neste ponto.

- Em que atividades o uso do cinema deixa de ser supérfluo e passa a ser essencial? 
- Como ensinar estruturas e outros elementos linguísticos básicos com o uso do cinema?

O fato de o cinema ser trabalhado fora de um contexto específico frequentemente esvazia a potência pedagógica desse recurso, que, se trabalhado de forma correta, pode ser um importante aliado para ampliar o repertório dos alunos (MAZZOCO, 2016, online). Com frequência, os filmes são utilizados para introduzir temas, oferecer material de áudio em um contexto mais autêntico e realizar análises em termos narrativos, de forma indistinta de um texto literário. Entretanto, ao conhecer um pouco mais sobre os elementos que caracterizam o cinema enquanto um meio específico, os professores poderão enxergar mais relações com os assuntos temáticos e estruturais de suas aulas. Embora muitas vezes a narrativa de um filme seja relevante e possa ser explorada didaticamente com os alunos, o filme não precisa ser tratado somente em aspectos narrativos, como se fosse uma obra literária, pois:

\footnotetext{
Quando vemos um filme, no entanto, não nos relacionamos apenas com sua forma. Vivenciamos um filme - não um quadro ou um romance. A análise de uma pintura exige um conhecimento a respeito de cor, forma e composição; a análise de um romance demanda conhecimento de Letras. Para entender a forma em qualquer arte, devemos nos familiarizar com o meio que essa arte utiliza. Consequentemente, nosso entendimento de um filme também deve incluir aspectos do meio fílmico. (BORDWELL \& THOMPSON, 2008, p. 111, tradução nossa ${ }^{9}$.
}

Em um artigo que relata uma experiência de ensino de LI com uso de filmes cinematográficos como ferramenta didático-pedagógica, Bacelar et al. (2013) exploram alguns tipos interessantes de atividades, concentrando-se na "possibilidade de nos transportar para a tela e sermos os protagonistas de muitas histórias além do plano real". Apontam que o aprendizado da LI pode ser enriquecido "fazendo uso desses efeitos cinematográficos onde a língua é enfocada como instrumento de comunicação no relato da história" (BACELLAR, p. 1, 2013). Embora apoiados mais pela sua intuição do que por um referencial teórico, os autores propõem o desenvolvimento de atividades didáticas que, conforme seu relato, surtiram efeitos positivos. As atividades basicamente se dividem em:

\footnotetext{
${ }^{9}$ When we see a film, though, we do not engage only with its form. We experience a film - not a painting or a novel. Analyzing a painting demands a knowledge of color, shape, and composition; analyzing a novel demands knowledge of language. To understand form in any art, we must be familiar with the medium that art utilizes. Consequently, our understanding of a film must also include features of the film medium.
} 


\section{LínguaTec}

(a) explorar os diálogos das personagens para exercícios de leitura e compreensão, para preenchimento de lacunas; (b) atividades de vocabulário, como um bingo com palavras retiradas de uma cena específica e palavras-cruzadas elaboradas com vocabulário das falas das personagens; (c) atividades inspiradas em temas e trechos de filmes, extrapolando seu universo narrativo e artístico, como uma atividade com uma música que é trilha sonora de um filme, a discussão de aspectos culturais trazidos pela história, a pesquisa por informações biográficas de um protagonista, a discussão de uma cena específica, a criação de um poema através de uma palavra-chave, o desenho de uma personagem; (d) a recontagem de partes específicas do filme. Os autores concluem que "os filmes cinematográficos são uma ferramenta didático-pedagógica poderosa na organização dos impulsos internos e criação de novos contextos de linguagem" (BACELLAR, p. 1, 2013), proporcionando o desenvolvimento das quatro habilidades e a aprendizagem de vocabulário e estruturas gramaticais.

Seguindo mais ou menos a mesma linha, mas com uma fundamentação teórica mais sólida, Araújo e Voss (2009) defendem que podemos explorar o cinema no ensino de LI como uma estratégia pedagógica ampla, centrada na sua capacidade de gerar identificação e projeção por parte dos alunos com relação ao mundo retratado de forma mimética pelos filmes, sobretudo os de ficção.

\footnotetext{
[u]tilizamos o cinema em sala de aula como uma estratégia que, ao simular a realidade, favorece o processo de identificação/projeção da experiência para acionar e possibilitar os processos cognitivos que envolvem a aprendizagem, consolidando os conteúdos estruturais e semânticos da LE. (ARAUJO \& VOSS, 2009, p. 120).
}

As autoras chamam a atenção para a escolha de filmes que consigam gerar esse tipo de identificação e projeção por parte dos alunos, ao abordarem temas pertinentes à realidade dos discentes, tais como temas universais e transversais, como direitos humanos, cidadania, meio ambiente, saúde, sexualidade, etc. Assim, reconhecendo na tela questões cotidianas suas, os alunos se identificam com as situações vividas pelas personagens e pela história construída pelo filme. Ademais, orientada pelo professor em discussões estruturadas a respeito de seus temas, a turma é incentivada a usar "o vocabulário acionado pelos sentimentos e emoções que emergem do enredo e de seus personagens" (ARAUJO \& 
VOSS, 2009, p. 127). A proposta das autoras capta um aspecto essencial do uso do cinema em sala de aula - não só de LI, mas no ensino de qualquer disciplina - , concentrando-se na seleção e no trabalho com os temas construídos e de certa forma explorados pelos próprios filmes, mas não explicita como os itens de vocabulário e de estrutura da língua podem ser abordados no contexto específico da linguagem do cinema ou do audiovisual enquanto meio artístico e de expressão. As suas proposições são muito válidas, portanto, e inclusive subjazem a proposta que ora desejamos desenvolver, mas, antes, como uma série de princípios mais gerais sobre um processo importante que é, sim, responsável pelo sucesso do uso do cinema em sala de aula, isto é, a relevância dos filmes enquanto aproximação da realidade dos alunos por meio de sua capacidade de gerar identificação e projeção, e como recurso considerado como gerador de motivação entre os alunos.

Não surpreende que as propostas de trabalho com cinema que aproximam a realidade dos alunos com o mundo retratado nas telas encontram respaldo nas pesquisas em linguística aplicada ao ensino do inglês relatadas por Lightbown e Spada (2008) sobre a importância de tornar a sala de aula um ambiente que promova a motivação dos alunos:

\begin{abstract}
Se conseguirmos tornar nossas salas de aula lugares para onde os alunos queiram vir porque os conteúdos são interessantes e relevantes para sua idade e seu nível de habilidade, onde os objetivos pedagógicos sejam desafiadores, mas possam ser viáveis e claros, e onde o clima seja de apoio e não de ameaça, estaremos dando uma contribuição positiva para que os alunos se sintam motivados a aprender. (LIGHTBOWN \& SPADA, 2008, p. 57, tradução nossa ${ }^{10}$ ).
\end{abstract}

Em uma proposta de três atividades específicas de ensino de LI com o cinema, Arizio Sweeting $(2010$, online) parte de objetivos didáticos para buscar nos filmes o caminho para potencializar esse aprendizado. A primeira atividade tem como objetivo fazer com que os alunos identifiquem o uso de sarcasmo e ironia, assim alcançando significados implícitos na linguagem de seus interlocutores. Estruturada em passos específicos, a atividade prevê a leitura e a interpretação do script de uma cena e o foco em aspectos fonológicos de tonicidade e entonação, posteriormente levando os alunos a produzirem diálogos. Na

\footnotetext{
${ }^{10}$ If we can make our classrooms places where students enjoy coming because the content is interesting and relevant to their age and level of ability, where the learning goals are challenging yet manageable and clear, and where the atmosphere is supportive and non-threatening, we can make a positive contribution to students' motivation to learn.
} 
segunda atividade, o autor parte da necessidade de integrar linguagem verbal e não verbal, enfatizando a função da linguagem corporal e expressões faciais para comunicar diferentes atitudes e emoções. Para tanto, Sweeting propõe uma sequência didática que inclui o ensino prévio de vocabulário, uma atividade interativa com base em mímica e, posteriormente, o trabalho com o script de uma cena do filme. Além disso, prevê que os alunos primeiro assistam ao filme sem som, para se concentrarem na expressão corporal dos atores, e só depois assistam à cena com o áudio.

A terceira e última atividade proposta é um exercício mais completo de áudio com preenchimento de lacunas, em que os alunos devem buscar sinônimos para palavras marcadas em negrito no script de uma cena do filme Muriel's Wedding (1994). Em um segundo momento, os alunos devem identificar cada trecho como um elogio ou depreciação com relação às personagens. $O$ autor aponta que, nesta última atividade, uma das vantagens é permitir que os alunos tenham a oportunidade de analisar a língua das cenas do filme com relação ao vocabulário e à função comunicativa antes de assistirem à cena. Com essas atividades, o autor destaca que os filmes, além de proporcionarem um ótimo contexto para o trabalho com análises linguísticas e prática das habilidades receptivas e produtivas,

\footnotetext{
fornecem aos alunos e ao professor textos de vida real que podem ser usados para estruturar uma consciência pragmática, principalmente na medida em que os filmes não discriminam o uso da linguagem, tornando o texto fílmico ideal para atividades de conscientização a respeito da adequação e de modelos de linguagem menos convencionais. (SWEETING, 2010, online, tradução nossa ${ }^{11}$ ).
}

O ponto forte dessas atividades propostas é que, partindo de componentes linguísticos desdobrados em objetivos didáticos, o autor busca nos filmes os elementos próprios da linguagem cinematográfica, principalmente da atuação (entonação e expressão corporal), para explorar partes específicas de filmes. A necessidade pedagógica subordina o material didático, neste caso o filme, mas encontra nele aspectos característicos que entrelaçam as atividades de maneira rica e contextualizada. Essas três atividades são casos concretos em que o uso do cinema deixa de ser acessório e passa a ser essencial, quiçá como

\footnotetext{
${ }^{11}$ provide both learners and teachers with real-life texts which can be used to scaffold pragmatic awareness, especially as films do not discriminate against language, making the text of film ideal for awareness-raising activities on appropriacy and less conventional language models.
} 
a melhor alternativa para ensinar esses componentes linguísticos. Entretanto, embora o autor não descreva o perfil das turmas que constituem o público-alvo dessas atividades, as três parecem pressupor um nível intermediário ou avançado de proficiência em LI, o que representaria um obstáculo para sua implementação em grande parte dos contextos do ensino básico de inglês no Brasil, onde prevalecem os níveis iniciais de proficiência, em que “o professor (e os materiais e técnicas) se torna um determinante central do sucesso dos alunos no alcance dos objetivos pedagógicos" (BROWN, 2007, p. 112, tradução nossa ${ }^{12}$ ). Portanto, ainda permanece a pergunta: como desenvolver sequências didáticas que aproximem aspectos linguísticos da linguagem cinematográfica (e vice-versa), mas que partam de conteúdos e objetivos pedagógicos elementares do ensino da LI? Em outras palavras, como ensinar estruturas, funções e vocabulários básicos de inglês de maneira mais efetiva com o uso de filmes?

\section{Aproximando a linguagem cinematográfica e a $\mathrm{LI}$}

É importante mantermos em mente que não estamos propondo uma caracterização do cinema como uma língua, para então definirmos quais de seus elementos correspondem ao sistema, pois de fato o cinema não é composto por um sistema de signos destinados à comunicação da mesma forma que uma língua. Como aponta Christian Metz, para cada aspecto que caracteriza uma língua, a linguagem cinematográfica revela um caráter diverso:

Ao léxico, sempre mais ou menos enumerável dos nossos idiomas, [o cinema] opõe a quantidade indefinida (e sempre crescente) das suas imagens: às codificações constitutivas da morfossintaxe (=gramática), opõe a abundância exuberante e aparentemente incalculável de seus arranjos de imagens, ou de seus arranjos de imagens e de falas; enfim, aos sistemas fonológicos nada tem a opor. (METZ, 1980, p. 339).

Embora reconheça a falta de correspondência perfeita e não problematizada entre um sistema de língua e o cinema, o autor conclui, na mesma obra, que quando comparado a

\footnotetext{
${ }^{12}$ the teacher (and the accompanying techniques and materials) becomes a central determiner in whether students accomplish their goals.
} 
outros sistemas de signos, o cinema pode ser estudado com relação às suas propriedades enquanto "linguagem", pois que, mesmo não sendo um sistema, o cinema contém vários.

O cinema, é verdade, não permite o jogo imediato da troca bilateral, mas não é o único conjunto semiológico a se comportar dessa forma; ninguém responde diretamente a um mito, a um conto popular, a um rito, a um sistema culinário ou de vestuário, a um trecho musical. (METZ, 1980, p. 341).

Ao cotejar a linguagem cinematográfica e o sistema de uma língua, Metz conclui que o máximo que se poder afirmar nessa aproximação é que "o plano cinematográfico não é, portanto, comparável à palavra de um léxico; em vez disso, ele lembra um enunciado completo (de uma ou mais frases), já que é o resultado de uma combinação essencialmente livre, um arranjo de 'fala'” (1992, p. 173, tradução nossa $\left.{ }^{13}\right)$. Embora não se possa buscar, como visto, uma correspondência perfeita entre a linguagem cinematográfica e as estruturas de uma língua, como a inglesa, é perfeitamente possível estabelecer relações com base nessas afirmações de Metz e de um exemplo concreto explorado pelo próprio autor, que se refere ao sintagma de alternância.

O sintagma de alternância, conforme a exposição de Metz (1992, p. 175-176), referese a um plano que alterna entre a imagem de uma mãe, a de sua filha e novamente a da mãe. Esse sintagma, então, constitui uma rejeição do agrupamento por uma série contínua, pressupondo o uso de edição em uma estrutura de campo-contracampo. Embora o autor reconheça, em nota de rodapé, que seria possível identificar outras implicações, no trabalho original ele analisou três tipos de denotações temporais resultantes desse sintagma. 0 primeiro caso seria o alternador, que demonstra uma série de ações ou eventos análogos, tais como ocorreria em um filme que mostra dois jogadores de tênis batendo na bola, um por vez. O segundo corresponde ao sintagma alternado, exemplificado por uma sequência cinematográfica de uma perseguição policial, por exemplo, em que acompanhamos ora o perseguido, ora o perseguidor, mas o espectador entende que está testemunhando acontecimentos que muitas vezes são simultâneos. O terceiro e último caso é o que o autor chama de sintagma paralelo, em que os eventos são combinados por meio de montagem,

\footnotetext{
${ }^{13}$ the shot is therefore not comparable to the word in a lexicon; rather it resembles a complete statement (of one or more sentences), in that it is already the result of an essentially free combination, a 'speech' arrangement.
} 
sem, no entanto, estabelecer qualquer relação no nível do significado (diegese), ao menos no que diz respeito à denotação. No exemplo da alternância entre uma cena de uma paisagem urbana noturna sinistra e, em seguida, uma cena pastoril ensolarada, não há nada que indique se essas cenas são simultâneas e, caso não sejam, qual ocorreu primeiro. Elas são articuladas, portanto, por razões simbólicas de montagem (ricos e pobres, vida e morte, etc.). É como se as relações temporais denotadas tivessem cedido à riqueza e à multiplicidade de valores da conotação.

Considerando os três tipos de sintagmas de alternância apresentados juntamente de seus exemplos prototípicos, podemos então nos perguntar quais componentes básicos da LI poderiam se relacionar com esse aspecto da linguagem cinematográfica. Seguindo esse raciocínio, não é difícil chegar à conclusão de que os marcadores discursivos que expressam uma sequência em uma narrativa seriam providencialmente trabalhados em uma cena de perseguição (first, next, following, then, later, etc.), bem como conjunções que expressem simultaneidade para o caso do sintagma alternador (while, meanwhile, whereas, in the meantime, etc.). Até mesmo conectores de coordenação (and, but, for, nor, yet, so) podem ser trabalhados no contexto desses sintagmas, principalmente o terceiro caso, em que as relações temporais dão lugar às conexões simbólicas e lógicas. Além disso, já que o sintagma trata, nos filmes, em sua maior parte de ações, sequências cinematográficas dos dois primeiros casos principalmente seriam um rico contexto para trabalhar com os tempos verbais present continuous ou past continuous, levando os alunos a identificar ou a produzir enunciados em LI do tipo: "A is running, while $B$ is riding a bike" ou " $A$ is shooting, but $B$ is hiding behind the wall". Longe de encerrar qualquer rol de possibilidades de conexões entre os sintagmas de alternância da linguagem cinematográfica e componentes linguísticos básicos da LI, esses exemplos servem apenas para mostrar que, depois de analisar de maneira mais detida um aspecto específico de um filme, não é difícil para o professor de LI tornar o ensino por meio de filmes uma maneira mais efetiva do que seria com qualquer outro recurso. Não se trata mais, portanto, de ilustrar um ponto ou um tema com o filme, mas antes de trazer o recurso audiovisual para o centro da atividade de aprendizagem da língua estrangeira. Embora as análises propostas por Metz possam parecer tecnicamente complexas e muito sofisticadas, a ponto de representar um obstáculo para alguns 


\section{LínguaTec}

professores que desejem implementar atividades com filmes em aulas de LI, a seguir vamos explorar uma dimensão mais prática e palpável, pensada para atender às necessidades do nosso contexto educacional.

\section{A mise-en-scène no cinema}

Visando atender à necessidade de nos familiarizarmos com alguns elementos-chave da linguagem cinematográfica para enriquecer nossas práticas em sala de aula, dedicamos esta seção à definição de um aspecto particular do cinema, que será utilizado nas propostas didáticas apresentadas posteriormente, quando serão retomadas as aproximações com as práticas pedagógicas.

Frequentemente negligenciamos as especificidades do cinema enquanto um meio e tratamos os filmes como se fossem narrativas de um livro. Assim, deixamos de perceber que complementares aos elementos que compõem a narrativa de um filme estão aqueles que constituem o seu estilo. O estilo de um filme pode ser discutido em termos da sua organização das técnicas cinemáticas da produção como um todo: a edição, o som, a cinematografia e a mise-en-scène. Dentre as técnicas cinemáticas que compreendem a construção de uma tomada, a mise-en-scène constitui o foco deste artigo, embora as outras técnicas também representem aspectos relevantes nas análises fílmicas e também possam enriquecer o ensino e a aprendizagem de línguas estrangeiras.

A escolha da mise-en-scène como foco desta proposta não é tão arbitrária quanto possa parecer. Dentre outras técnicas que compõem o estilo de um filme, como a cinematografia, o enquadramento, as relações rítmicas, espaciais e temporais entre as tomadas (edição), bem como as dimensões e funções do uso do som, a mise-en-scène é a que trabalha os aspectos mais facilmente percebidos pelos espectadores, tais como a atuação, o figurino e o cenário. Tanto isso é verdade que "grande parte das nossas memórias mais marcantes de filmes se concentra em elementos da mise-en-scène" (BORDWELL \& THOMPSON, 2008, p. 112 , tradução nossa ${ }^{14}$ ). Isso facilita a apresentação da proposta

\footnotetext{
${ }^{14}$ many of our most sharply etched memories of the cinema turn out to center on mise-en-scene.
} 
enquanto uma tentativa ainda incipiente de aproximar a linguagem cinematográfica do ensino de LI, pois mesmo não tendo um conhecimento técnico específico sobre edição, por exemplo, grande parte dos professores sente-se à vontade para trabalhar questões pertinentes ao cenário de um filme em relação à sua narrativa como um todo.

Mas afinal, o que é a mise-en-scène? Termo originalmente usado no teatro, significa "colocar em cena" e compreende o cenário, o figurino e a maquiagem, a iluminação e o comportamento das figuras. Esses elementos são, até certo ponto, controlados pelo diretor para "encenar um evento diante da câmera" (BORDWELL \& THOMPSON, 2008, p. 112, tradução nossa ${ }^{15}$ ). É importante considerar esses elementos em qualquer filme, mas principalmente analisar como certos padrões e motivos funcionam no filme como um todo.

Com relação ao cenário, o cineasta pode escolher entre construir um ou filmar a ação em um local já existente. Ao construir um cenário, os diretores podem enfatizar a autenticidade histórica ou um mundo estilizado de fantasia. Entretanto, é importante não supervalorizar a autenticidade histórica em detrimento da fantasia com base no realismo, uma vez que o realismo de um cenário é uma questão de convenções espectatoriais. O que nos parece realista hoje pode parecer estilizado para espectadores no futuro. Para a análise cinematográfica, mais interessante que a questão da autenticidade é questionar como o cenário pode orientar a nossa compreensão da história do filme. Isso pode ser realizado considerando-se a relação entre as personagens e o cenário, o uso das cores e de props objetos no cenário que possuem uma função ativa na ação que se desenrola (cf. BORDWELL \& THOMPSON, 2008, p. 115-117).

Assim como o cenário, o figurino e a maquiagem podem ser construídos para contribuir para a organização total de um filme. O figurino também pode ser mais ou menos autêntico ou mais ou menos estilizado. Qualquer item do figurino de uma personagem pode também se tornar um prop - óculos, uma arma ou uma capa, por exemplo. Filmes de diferentes gêneros, tais como musicais, filmes de aventura ou de detetive, associam as suas personagens a props específicos - o guarda-chuva voador de Mary Poppins, a máscara do Zorro, a lupa de Sherlock Holmes e o sapatinho de rubi de Dorothy em O mágico de Oz. Além disso, a análise de como o cenário e o figurino se coordenam em um filme pode revelar

\footnotetext{
${ }^{15}$ the director stages the event for the camera.
} 
muito sobre sua contribuição para a produção como um todo. Assim como o figurino e o cenário, a maquiagem contribui de forma significativa para a organização total de um filme, conferindo maior ou menor grau de autenticidade histórica ou estilização (cf. BORDWELL \& THOMPSON, 2008, p. 121-124).

Outro aspecto da mise-en-scène que é controlado para alcançar certos efeitos e orientar a experiência do espectador é a iluminação. Existem diversas combinações e variáveis na utilização da luz no cinema. A iluminação pode criar áreas de destaque e sombras. Áreas de destaque são porções brilhantes em uma superfície, enquanto as sombras podem ser de dois tipos: a sombra própria, quando a luz deixa de iluminar parte de um objeto por causa do seu formato ou das características de sua superfície, e a sombra projetada, quando um corpo ou um objeto bloqueia a luz, projetando a sombra sobre outro objeto ou corpo (cf. BORDWELL \& THOMPSON, 2008, p. 124-126).

Além de áreas de destaque e sombras, a iluminação pode ser analisada quanto à qualidade, à direção, à fonte e à cor. A qualidade se refere à intensidade da luz, que pode ser dura, criando sombras bem definidas, ou suave, produzindo uma iluminação difusa. A direção diz respeito à trajetória da luz desde a sua fonte até o objeto iluminado. A direção da fonte de iluminação pode ser classificada como frontal, lateral, contraluz, inferior e superior. Além disso, a iluminação possui dois tipos de fonte: a luz principal e a luz de preenchimento. A luz principal fornece a fonte primária de iluminação, enquanto a luz de preenchimento suaviza as sombras projetadas pela principal (cf. BORDWELL \& THOMPSON, 2008, p. 126128).

Em Hollywood e em outros cinemas que seguem as suas convenções, tornou-se uma prática padrão a adoção de um sistema de iluminação de três pontos, que consiste em uma luz principal, uma luz de preenchimento e uma contraluz. Esse sistema de iluminação de três pontos também está ligado a uma iluminação principal alta, que utiliza a luz de preenchimento e a contraluz para reduzir o contraste entre as áreas mais claras e as mais escuras. Esse sistema de iluminação, identificado com o cinema hollywoodiano clássico, é um dos elementos responsáveis por causar a impressão de invisibilidade do aparato cinematográfico. A iluminação principal baixa, ao contrário, produz mais contraste e sombras escuras. Esse sistema foi muito utilizado em filmes noir (uma técnica conhecida 
como chiaroscuro), criando um clima sombrio e de suspense (cf. BORDWELL \& THOMPSON, 2008, p. 130-131).

A iluminação é essencial para reconhecermos inovações e questionamentos no campo estético e, até mesmo, ideológico. São exemplos do uso de chiaroscuro os filmes Cidadão Kane (1941) e A Marca da Maldade (1958), ambos de Orson Welles. No Brasil, Bellini e a Esfinge (2001) evoca essa atmosfera sombria, embora não passe de um pastiche do gênero de detetive do tipo noir, que constituiu uma chamada à realidade angustiante dos Estados Unidos do pós-guerra frente ao mundo de doçura de Hollywood.

Finalmente, a mise-en-scène compreende o comportamento das figuras. Figuras referem-se não só a atores e atrizes, mas também a animais, robôs, objetos e basicamente qualquer coisa que a mise-en-scène permita a expressão de sentimentos e pensamentos. Contudo, atores que interpretam papéis constituem uma categoria intuitivamente mais familiar. Ainda que a representação seja com frequência avaliada com base no realismo, existem muitas objeções a esse critério. Primeiro, como já foi mencionado com relação ao cenário, as noções de um comportamento realista podem mudar com o tempo, e o que parece realista hoje pode parecer estilizado uma década ou duas depois. Segundo, alguns filmes obviamente não almejam representar o mundo de maneira realista (Como seria uma representação realista do Saci-Pererê?). Em geral, a representação dos atores pode ser analisada em termos de individualização, estilização e tipo (e, por consequência, estereótipo). Porém, o mais importante é considerar a articulação da atuação com os outros aspectos da mise-en-scène, com o estilo total e com as convenções de gênero do filme (cf. BORDWELL \& THOMPSON, 2008, p. 136-140).

Ao manipular a mise-en-scène, o cineasta concebe o espaço e o tempo, guiando a nossa compreensão de um dado filme. Embora a tela seja um espaço bidimensional, a função da mise-en-scène é justamente apresentar o espaço tridimensional da ação. Construímos uma impressão de espaço na tela principalmente através da percepção de mudanças de diferentes tipos: movimento, diferenças de cor, equilíbrio entre componentes distintos e variações de tamanho. Esses elementos constituem pistas de profundidade, que sugere que o espaço na tela possui volume e diferentes planos. O volume de um objeto é a ideia de que ele é sólido e que ocupa uma área tridimensional, enquanto os planos são 


\section{LínguaTec}

camadas do espaço ocupado por pessoas e objetos (fundo, plano médio, primeiro plano e muitas outras posições intermediárias). Embora a relação entre o tempo e a mise-en-scène ainda não seja compreendida suficientemente, ela envolve a análise de padrões de ritmo e sincronia da ação. Além disso, é importante analisar quando os espectadores são levados a perceber certos aspectos da mise-en-scène e por quanto tempo, bem como as implicações que esse direcionamento pode ter sobre a forma e o estilo total do filme (cf. BORDWELL \& THOMPSON, 2008, p. 140-153).

\section{Mise-en-scène: algumas possibilidades de aplicação em sala de aula}

Levando em consideração essas características da mise-en-scène apenas superficialmente apresentadas, podemos começar a refletir sobre algumas atividades que podem ser elaboradas para o ensino de LI, tomando como ponto de partida não o filme, nem o elemento teórico, mas antes a necessidade pedagógica, o objetivo didático e o conteúdoalvo em termos linguísticos, a exemplo da proposta de atividades pedagógicas que desenvolvemos e apresentamos anteriormente (PEREIRA, TEIXEIRA \& ESPÍDULA, 2017) para o ensino da função de descrever uma cena externa com o uso das estruturas there is/are, com o auxílio do filme antológico L'Arroseur Arrosé (O Regador Regado), de 1895, de Louis Lumière, considerado como o precursor do gênero de comédia no cinema mundial.

Assim, serão apresentados a seguir dois conjuntos de atividades pedagógicas para o ensino de inglês que se concentram na articulação de elementos da mise-en-scène com aspectos linguísticos a serem ensinados. Nessa aproximação com o cinema, gostaríamos de salientar que não defendemos a identificação de aspectos exclusivamente estruturais da língua a ser ensinada, pois os contextos de produção e de circulação dos filmes como bens culturais enriquecem a aprendizagem e devem ser explorados de forma integrada ao ensino de componentes linguísticos. Por isso, as atividades apresentadas a seguir representam apenas duas possibilidades de abordagem de filmes, embora seja possível o desenvolvimento de muitas outras vias de acesso. Na primeira, no caso das atividades com o filme $A$ vingança dos Sith, partimos do objetivo, previsto em um plano de ensino, que os 
alunos saibam utilizar wh-question words e o presente simples, aspectos estruturais da língua. Na segunda série de atividades, o objetivo da lição parte de elementos funcionais da língua, considerando que, como precursores da abordagem comunicativa no ensino de línguas estrangeiras, os programas funcionais (functional syllabuses) continuam embasando muitos materiais didáticos até os dias atuais (cf. BROWN, 2007, p. 34-35). Assim, as atividades com o filme Os estagiários concentram-se nos componentes linguísticos e até culturais envolvidos em saudações e apresentações pessoais. Apesar de representarem tendências bastante difundidas no ensino da LI no contexto atual do ensino público brasileiro, essas duas formas de lidar com a linguagem cinematográfica não encerram as possibilidades de abordagem de filmes a partir de elementos linguísticos ${ }^{16}$.

Assim, vamos considerar um caso concreto do plano de ensino do primeiro trimestre da disciplina de LI I do curso técnico em informática integrado ao ensino médio do campus Osório do IFRS. Na lista de conteúdos para o primeiro trimestre da disciplina, temos o seguinte:

- Reading strategies

- Using a bilingual dictionary

- Countries and nationalities

- Verb to be

- Wh-question words

- Personal habits and traditions

- Brazilian food

- Simple present

- Adverbs of frequency

A atividade descrita a seguir é apenas um exemplo de como aproximar um aspecto da miseen-scène de um filme com um tópico específico e básico de forma que o filme se torne um elemento essencial para o aprendizado dos alunos. A cena trabalhada é a abertura do episódio II da saga Star Wars, A vingança dos Sith (Fox, 2015). Ela mostra Anakin Skywalker e Obi-Wan Kenobi se aproximando da nave de comando do General Grivous, que havia sequestrado o Chanceler Palpatine. Eles enfrentam alguns obstáculos, como Buz Droids e mísseis, até entrar na nave e iniciar a busca. A cena toda dura pouco mais de seis minutos.

\footnotetext{
${ }^{16}$ Seria interessante desenvolver atividades que aproximem a linguagem cinematográfica de elementos do ensino da LI a partir de uma abordagem com base em gêneros textuais, por exemplo.
} 
Star Wars é uma saga muito relevante na vida dos adolescentes das turmas do primeiro ano do curso técnico em informática integrado ao ensino médio, então, além de eles se interessarem muito por atividades com qualquer filme da saga, eles passam a desempenhar um papel totalmente ativo na aula, ajudando o professor com detalhes sobre a história, a produção, os atores, etc., além de ocasionalmente polemizar e corrigir alguns colegas a respeito de pormenores do filme, o que obviamente deve ser mediado pelo professor. Em termos da linguagem cinematográfica, a cena inicial desse filme é um grande espetáculo de cenário, luzes e sons, o que chama a atenção dos espectadores para sua mise-en-scène. A proposta, então, dando sequência ao trabalho de revisão de estruturas com o verbo to be, é enfatizar e praticar wh-question words para explorar um pouco desses elementos espetaculares.

A atividade é dividida em quatro partes. No primeiro passo, que consiste em uma contextualização do filme e da atividade, o professor mostra à turma um texto que é tradicionalmente exibido no começo das produções de Star Wars, o que já revela o filme e introduz os elementos narrativos básicos da cena que será trabalhada. No slide, os alunos fazem a seguinte atividade:

Read the text below. Can you guess what movie this is? Try and complete the gaps.

A in a galaxy far, far away...

\section{Episode III}

Revenge of the Sith

War! The Republic crumbling under attacks by the ruthless Sith Lord, Count Dooku. heroes on both sides. Evil everywhere.

In a stunning move, the fiendish droid leader, General Grivous, has swept into the Republic capital and kidnapped Chancellor Palpatine, leader of the Galactic Senate.

As the Separatist Droid Army attempts to flee the besieged capital with their valuable hostage, two Jedi Knights lead a desperate mission to rescue the captive Chancellor...

Note que essa atividade é apresentada antes de assistirmos à cena, portanto os alunos ativam o seu conhecimento prévio sobre o assunto e, à medida que completam as lacunas, tornam-se bastante entusiasmados com o filme em questão. A primeira frase: "A long time ago in a galaxy far, far away..." é a frase de abertura da maioria dos filmes de Star Wars, e as 
outras lacunas são palavras gramaticais relacionadas ao verbo to be, mas vão apresentando o texto que contextualiza a ação de maneira indireta.

Como um segundo passo, o professor diz que reproduzirá aproximadamente seis minutos do filme e que os alunos devem prestar muita atenção em todos os detalhes, pois terão que responder a questões bem específicas a respeito da cena. Posteriormente, então, conforme orientado, o professor apresenta as questões, que são respondidas uma a uma pelos alunos da turma. Eis as perguntas:

- How many turbines are there in Anakin Skywalker's and Obi-Wan's aircrafts? (Two in each aircraft).

- What color is Anakin's aircraft? (Yellow).

- How many missiles are fired against Skywalker? (Four).

- What color is R4? (Red).

- Which wing of Obi-Wan's aircraft is shot? (The left one).

- What does R2 do when they enter the command ship? (R2 locates Senator Palpatine).

Observe que todas as perguntas iniciam com uma wh-question word, e a maioria envolve o verbo to be, a última trazendo elementos do presente simples e seu auxiliar does na terceira pessoa, como um desafio extra.

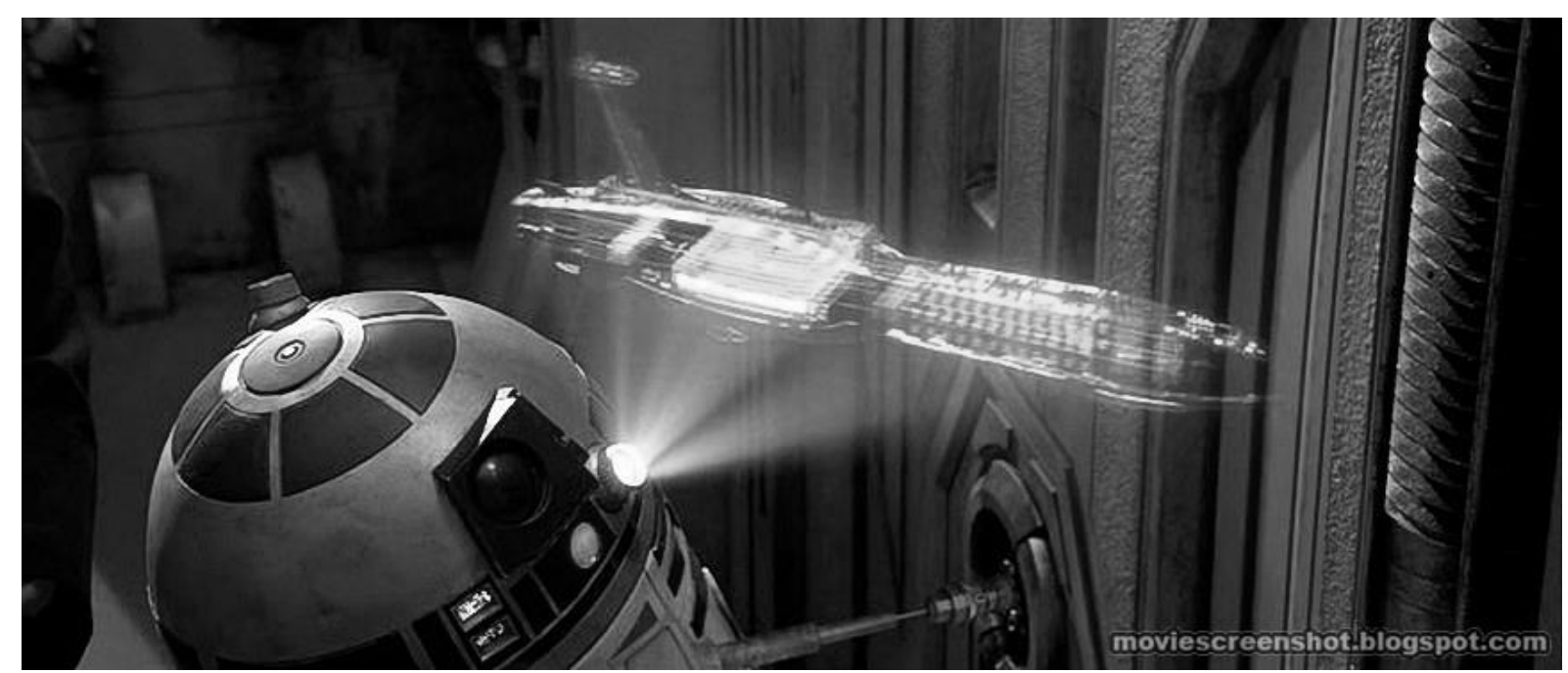

Imagem 1. Ao final da cena utilizada nesta atividade com o filme $A$ vingança dos Sith, da saga Star Wars, R2D2 usa suas capacidades técnicas para visualizar o mapa da nave

Fonte: Movie Screenshots. Disponível em: <http://moviescreenshot.blogspot.com.br/2011/07/star-warsrevenge-of-sith-movie.html>. Acesso em: 30 dez. 2017. 


\section{LínguaTec}

O terceiro passo consiste na montagem das equipes e na preparação de perguntas, para a posterior interação verbal entre os times. O professor divide a turma em dois grupos, distribuindo pedacinhos de papel azuis ou vermelhos (em Star Wars, o azul representa o lado da luz, enquanto o vermelho simboliza o da sombra), e orienta os alunos que preparem 10 perguntas com wh-question words e presente simples sobre a cena seguinte (que também dura aproximadamente cinco minutos) para desafiar o grupo oponente. Eis o que consta no slide:

In groups, prepare 10 questions to challenge the other team. Use:

- Where

- What

- Who

- How many

- When

- Which

- How much

Right questions count as 1 point.

Right answers count as 1 point.

Perceba que, na parte inferior do slide, constam as regras de pontuação para a etapa posterior da atividade. Assim, dividimos o peso entre o conteúdo e a forma, valorizando o seu conhecimento e sua perspicácia, mas também reconhecendo o mérito do grupo com relação à acurácia no uso das formas.

No quarto e último passo, o momento do desafio entre as equipes, o papel do professor é mediar a interação e explicar caso alguma pergunta tenha sido formulada com erro, o que se torna alvo de enorme interesse dos alunos pela forma da língua.

Esperamos que essa atividade com um filme da saga Star Wars demonstre que não se trata de teorizar sobre as cenas do ponto de vista da linguagem cinematográfica, mas de articular alguns elementos da mise-en-scène dessa sequência fílmica de maneira a construir atividades pedagógicas sólidas e fortemente relacionadas ao plano de ensino da disciplina, de maneira a tornar o uso do audiovisual um recurso fundamental para o aprendizado da língua estrangeira. 
A segunda série de atividades didáticas parte da observação de que os materiais disponíveis no Programa Nacional do Livro Didático (PNLD) para o ensino da LI não oferecem um foco para o ensino técnico em informática integrado ao ensino médio, ficando a cargo do professor (a) apenas seguir o material didático como se apresenta ou (b) suplementar o material didático de forma a oferecer aos alunos a aprendizagem da língua estrangeira no contexto de seu ensino técnico. Para os professores que desejam ir além do material didático e oferecer estruturas, vocabulário e contextos comunicativos relevantes às áreas de formação técnica dos alunos do ensino médio integrado do IFRS, o uso do cinema pode servir como uma possibilidade concreta e interessante para se atenderem tais necessidades.

Vamos tomar como exemplo a primeira unidade do livro didático Alive High 1 (2013), escolhido no campus Osório do IFRS para o ensino médio no período 2017-20. A primeira unidade apresenta, entre outros, os seguintes objetivos didáticos: greeting and introducing, understanding nonverbal signs, giving information about you and others. Ao longo da unidade, com materiais de áudio, leitura, comunicação, personalização das atividades, proposta de elaboração de um blog, etc., são mencionados dois filmes, Patch Adams (p. 17) e The Express (p. 22), mas não é sugerido ao professor trabalhar com cenas dessas obras. Apesar disso, as estruturas e o vocabulário utilizados para que o aluno se apresente e apresente outra pessoa são bem contextualizados. Dessa forma, podemos levantar a seguinte questão, para então aplicarmos nossa proposta metodológica com o intuito de enriquecer os materiais já organizados no livro com o uso do cinema: como uma cena de filme pode ajudar o aluno a entender melhor a função comunicativa de greetings e introductions e, a partir disso, se expressar mais efetivamente? Assim, buscando um filme que se passe em um contexto da Tecnologia da Informação, chegamos à produção Os Estagiários (2013), em que dois amigos se deparam com o desemprego e tentam um estágio na empresa Google.

No filme, existem várias cenas de apresentações pessoais (introductions), dentre as quais algumas funcionam como pontos de virada narrativa e trazem grande significado para a compreensão do filme como um todo. A primeira ocorre quando os protagonistas Bill e Nick participam de uma entrevista de seleção de estágio com os funcionários da Google, por videoconferência. A segunda acontece quando Nick se apresenta para Dana Simms, por 
quem ele se interessa, assim configurando o subenredo romântico do filme. A terceira cena de apresentações que pode ser explorada de acordo com esta proposta ocorre na cerimônia de abertura do programa de estágio, em que o arqui-inimigo da dupla, chamado Graham, se apresenta a Bill pensando que, por este ser mais velho, devia ser alguém importante na empresa. Por fim, outra cena de apresentações pessoais se passa logo em seguida a essa cerimônia de abertura, durante a montagem das equipes de estagiários, quando Lyle, um dos gestores da empresa, monta seu time com todos os rejeitados pelos grupos, incluindo, logicamente, a dupla de amigos Bill e Nick. Nesta última cena, a propósito, ocorre uma pequena discussão sobre a adequação de dizer algo enquanto se faz o gesto de fisting, o que denota o esforço do nerd Lyle em ser casual, quando na verdade não possui muitas habilidades interpessoais.

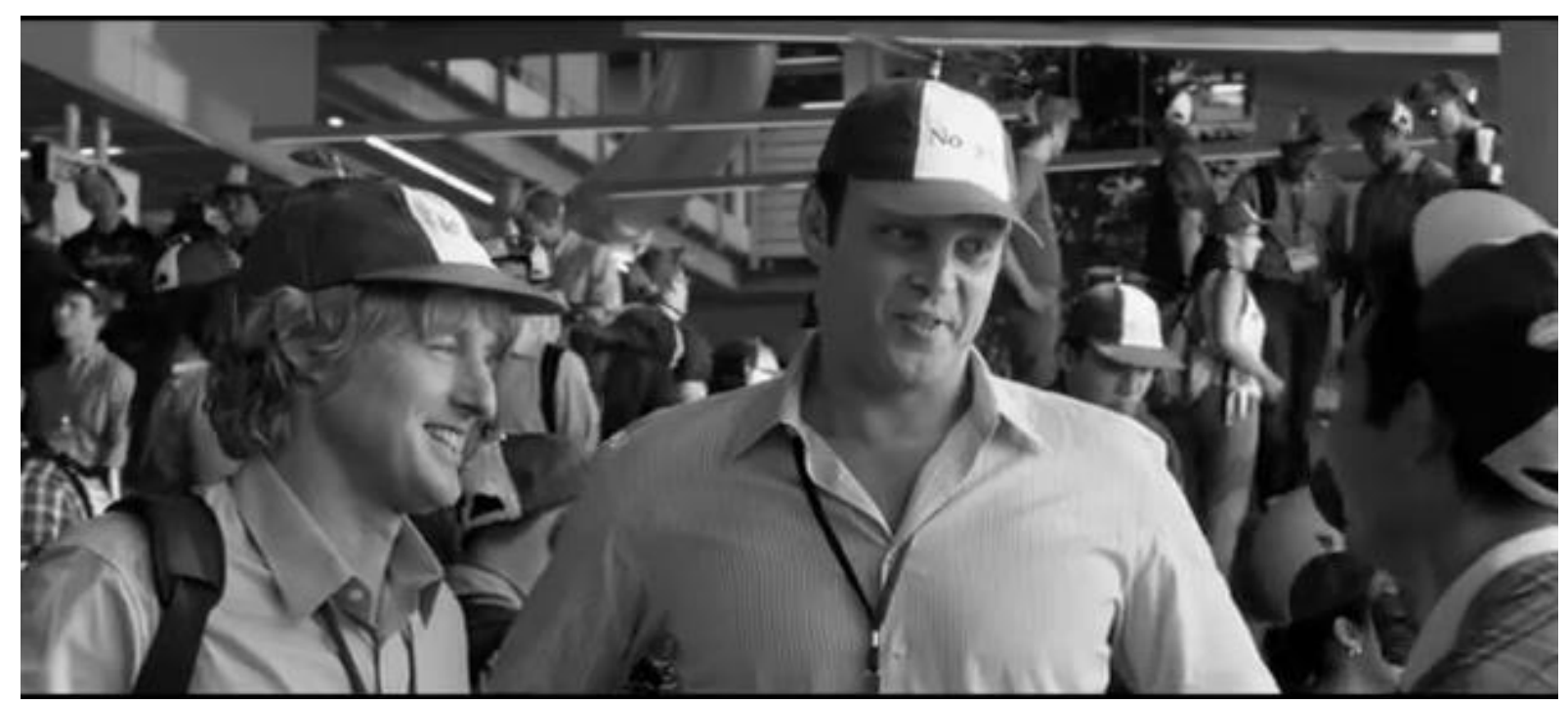

Imagem 2. Cena em que Graham se apresenta a Bill no filme Os estagiários

Fonte: HBWatch. Disponível em: < http://hbowatch.com/movie-review-the-internship/>. Acesso em: 30 dez. 2017.

Dentre inúmeras possibilidades, sugerimos o uso de duas cenas, mas, dependendo da disponibilidade de tempo e vontade do professor e da turma, as outras cenas poderiam também ser exploradas. Primeiro, o professor anuncia que irá mostrar uma cena de um filme e pede que os alunos adivinhem de que filme se trata. Então, é feita a exibição da segunda cena do filme, logo depois que a esposa de Bill decide deixá-lo. A cena, que dura aproximadamente um minuto, mostra Bill em frente ao computador, em uma saleta escura, procurando uma oportunidade de emprego pela Internet. Essa cena é interessante porque 


\section{LínguaTec}

contextualiza o filme e mostra alguns elementos ligados a partes de um computador. Depois de assistirem à cena, os alunos podem responder a essas questões:

- What is he doing? (He is looking for a job).

- What do you see on the screen? (An old desktop computer, a monitor, a mouse, a keyboard, a search engine, a lot of paper, a telephone, a fax, a lampshade, etc.).

- What is he thinking? (Probably "I need to find a job").

- What does he realize? (I could work at Google).

Depois de responder a essas questões e conversar com os alunos sobre o filme, que certamente alguns terão visto, observe com a turma que a personagem quase não fala, mas muitas informações são construídas apenas com a sua atuação e com o cenário, elementos da mise-en-scène. Note que existe uma brincadeira com as expressões "Google Search" e "I'm feeling Lucky". A busca-padrão não dá resultados bons para Bill, então ele provavelmente se detém na frase "Estou com sorte", o que se torna um motif ao longo do filme, em que os dois amigos nunca perdem o otimismo, mostrando que é preciso acreditar e perseguir seus sonhos. Outra questão interessante que o professor pode explorar com a turma é que, quando Bill tem a ideia de buscar a palavra Google, o ponto de vista não é mais o da personagem, mas do próprio computador. É como se a ferramenta de busca fosse personificada e cogitasse dar uma chance a esse pobre homem, pois é exatamente isso que acontece no desenrolar do filme.

Depois dessa contextualização do filme, sugere-se um trabalho com a cena cinco, em que a dupla de amigos faz a entrevista de estágio, por videoconferência, com o pessoal da Google. Logo que a tela mostrar o local em que eles estão e os dois sentados em banquinhos infantis a uma mesinha, apertados para poderem aparecer na mesma tela, o professor congela a reprodução para a turma analisar alguns elementos significativos do cenário e do figurino, que serão importantes para a compreensão do diálogo que verão a seguir. Então, os alunos podem responder a perguntas como estas, ou, alternativamente, o professor pode fazer dessas questões um exercício de verdadeiro ou falso. Antes de reproduzir o restante da 
cena, o professor chama a atenção da turma para o fato de que os alunos não precisam entender cada palavra para responder às perguntas.

- Where are they? (At a public library).

- Who else do you see? (Many kids).

- What are the characters' names? (Bill, Nick, Benjamin and Allison).

- Do they use a formal or informal way of introducing themselves? (Informal)

- When you go for an interview like this, you take care of every detail to make a good impression. Do you think they will make a good impression? Why? (No, because they are sitting on little stools for children, because children are around them, because they are old for an internship, etc.).

Após avançar o filme em alguns segundos, o professor pode se deter no diálogo que ocorre depois que a menina recebe o dinheiro para comprar um refrigerante e não os incomodar (17'17"). Nesse diálogo, substituindo o do livro didático Alive High 1 ou complementando o exercício apresentado na p. 22, o professor pode montar um handout ou projetar o texto da conversa em um slide. Entretanto, antes de mostrar a legenda ou projetar esse texto, sugere-se que os alunos assistam à cena com o som desabilitado, para que prestem atenção à riqueza da atuação, sugerindo um diálogo curto entre elas. Os alunos podem escrever esses diálogos, enquanto o professor circula pela sala, prestando auxílio e conversando sobre os pormenores da cena. Eles também podem fazer uma leitura dramática de suas produções para a turma ou em pequenos grupos. Depois, o professor mostra a cena com áudio e os alunos podem avaliar se suas interações estão parecidas com a original. Posteriormente, a turma ainda pode trabalhar com o texto que trata das apresentações da entrevista.

Bill: Here they are. When I hit this, they will be able to see us.

Bill: Get in close so they can see us. The webcam is small. Come here. Cheek to cheek.

Nick: Don't crowd me. You're crowding me.

Bill: Get cheek to cheek.

Nick: Yeah, but you're crowding me.

Bill: They can't see us.

Nick: I understand that.

Benjamin: We can see you guys.

Bill: Ok. Great! Hi, my name is Billy.

Allison: We can hear you fine as well.

Bill: Good. Billy MacMaham.

Nick: Nick Campbel. 
Benjamin: I'm Benjamin.

Allison: Allison.

De fato, em termos linguísticos, essa cena é bastante simples. As personagens usam estruturas informais para se apresentarem. Entretanto, a sua riqueza e graça estão justamente no gestual dos funcionários da Google e o quão desajeitados Bill e Nick são com o computador, justamente em uma entrevista para trabalhar em uma das maiores empresas do ramo! Algumas perguntas que podem nortear a compreensão dos alunos nesse sentido são:

- Underline the lines spoken by the Google employees. Why do they say that? (Benjamin says "We can see you guys." because Bill and Nick think they do not fit the screen, and Allison says "We can hear you fine as well" because they were shouting unnecessarily).

- Do you think they are strong candidates? (Apparently not, because they don't know how to deal with computers).

Essa cena mostra que elementos da mise-en-scène como gestos da atuação e cenário são responsáveis por grande parte de nossa compreensão de uma comunicação tão rotineira como uma apresentação pessoal. Essas atividades são de fato bastante simples, mas ao mesmo tempo estão intimamente ligadas aos objetivos pedagógicos da unidade de ensino em que elas foram propostas. Muitas outras cenas poderiam ser exploradas para fins semelhantes nesse filme, levantando questões linguísticas e até culturais, como o comportamento diferente dos nerds e o comportamento esperado de alguém que queira ter sucesso em uma carreira em Tecnologia da Informação.

\section{Considerações finais}

Ao identificarmos um caminho para trabalhar o cinema no ensino de LI de maneira mais estruturada, pedagogicamente sólida e de forma que os filmes se tornem ferramentas essenciais para alavancar o aprendizado dos alunos, confrontamo-nos com a necessidade de uma enorme tarefa de mapeamento. Se admitirmos que é realmente desejável estabelecer 


\section{LínguaTec}

relações entre a linguagem cinematográfica e componentes estruturais, lexicais, funcionais e culturais no ensino de LI, pois essa é uma via fértil para potencializar resultados de aprendizagem, ainda será necessário mapear uma virtual infinidade de relações entre esses componentes linguísticos e várias outras técnicas usadas no cinema, tais como a cinematografia, a edição e o som, apenas para citar os grandes grupos, que se subdividem em muitos outros recursos.

Para termos uma ideia de como esse campo ainda pode ser explorado, abrindo múltiplas vias de acesso para relações com o ensino de inglês e de outras línguas estrangeiras, vejamos o exemplo do uso do som. O som de um filme inclui questões de mixagem e sobreposição de sons, noções de ritmo, espaço (som diegético e não diegético) e tempo (som simultâneo e não simultâneo), pois a continuidade no cinema depende em grande parte do seu uso. Atividades de ensino de LI que se concentrem nos elementos sonoros de um filme podem levar em consideração as falas de personagens (monólogos e diálogos) em contextos específicos de produção e recepção, seu grau de formalidade, os sotaques e seus significados culturais, bem como as narrações em voice-over e voice-off e suas implicações para a construção de sentido do filme (em termos narrativos e de seu estilo). Além disso, os filmes sempre dependem muito de sons que não são emitidos por personagens, mas que contribuem para o sentido total da produção: ruídos de objetos do cenário, sons da natureza e trilhas sonoras. Tudo isso representa apenas uma pequena fração do que o cinema oferece ao professor de LI que desejar desenvolver atividades pedagógicas e atrelar seus objetivos pedagógicos ao uso do som no cinema.

Como é possível perceber, este artigo trouxe algumas respostas com relação a uma possível proposta metodológica de aproximação de elementos da linguagem cinematográfica e o ensino da LI, mas, ao mesmo tempo, levantou uma série de questões que permanecem abertas para educadores interessados em desenvolver pesquisas nessa área.

\section{REFERÊNCIAS}


ARAUJO, A. R.; VOSS, R. C. R. Cinema em sala de aula: identificação e projeção no ensino/aprendizagem da Língua Inglesa. Conexão, Comunicação e Cultura (UCS). v. 8, n. 15. 2009.

BACELLAR, F. et al. Utilizando filmes cinematográficos como ferramenta didático-pedagógica no aprendizado da Língua Inglesa. 11.a Mostra Acadêmica UNIMEP. Disponível em: www.unimep.br/phpg/mostraacademica/anais/4mostra/pdfs/237.pdf. Acesso em: 29 nov. 2017.

BORDWELL, D.; THOMPSON, K. Film Art: an introduction. New York: McGraw-Hill, 2008.

BROWN, H. D. Teaching by Principles: an interactive approach to language pedagogy. 3ed. New York: Pearson Education, 2007.

CANAL, A. O cinema nas aulas de espanhol. LínguaTec. Bento Gonçalves, v. 2, n. 3, p. 100-13, jun. 2017.

KHAN, A. Using Films in the ESL Classroom to Improve Communication Skills of Non-Native Learners. ELT Voices-International Journal for Teachers of English. Volume (5), Issue (4), 4652 (2015).

L'ARROSEUR ARROSÉ (O Regador Regado). Dir. Louis Lumière. França: Louis Lumière, 1895. Disponível em: <https://www.youtube.com/watch?v=4nj0vEO4Q6s>. Acesso em $06 \mathrm{fev}$. 2018.

LIGHTBOWN, P. M.; SPADA, N. How Languages are Learned. 2. ed. Oxford: OUP, 2008.

MAZZOCO, B. Como trabalhar filmes nas aulas de inglês. Nova Escola. Acesso em: 29 ago. 2016. Disponível em: <https://novaescola.org.br/conteudo/254/como-trabalhar-filmes-nasaulas-de-ingles>.

MENEZES, V. et al. Alive High 1: língua estrangeira moderna inglês - 1. ano do ensino médio. São Paulo: SM, 2013.

METZ, C. Some points in the semiotics of the cinema. In: Braudy, Leo; Cohen, Marshall (ed.). Film Theory and Criticism: introductory readings. New York and Oxford: OUP, 1992. . Linguagem e Cinema. Trad. Marilda Pereira. São Paulo: Perspectiva, 1980.

OS ESTAGIÁRIOS. Dir. Shawn Levy. Estados Unidos: $20^{\text {th }}$ Century Fox, 2013. DVD.

PEREIRA, M. R.; TEIXEIRA, C. M. S. P. G.; ESPÍNDULA, D. S. As relações entre a linguagem cinematográfica e o ensino de inglês: o exemplo do primeiro cinema. 7. a Mostra de Ensino, Extensão e Pesquisa. IFRS - Campus Osório. 18 e 19 set. 2017. Acesso em: 11 mai 2018. 
Disponível em: https://moexp.osorio.ifrs.edu.br/uploads/anai/2017/Anais MoExP 2017.1201.pdf

STAR WARS: Episódio III - A Vingança dos Sith. Dir. George Lucas. Estados Unidos: Lucasfilm, 2005. DVD.

SWEETING, A. Activities for using films in English language teaching. In: International House Journal of Education and Development. Issue 29. Outono de 2010. Disponível em: $<$ http://ihjournal.com/activities-for-using-films-in-english-language-teaching-by-ariziosweeting>. Acesso em: 23 ago. 2017.

Data de submissão: 15/04/2018. Data de aprovação: 07/05/2018. 